\title{
ARCHAEOMAGNETIC STUDIES IN KILNS FROM N. GREECE
}

\author{
Aidona E. ${ }^{1}$, Kondopoulou D. ${ }^{1}$, Alexandrou M. ${ }^{1}$, and Ioannidis N. ${ }^{1}$ \\ ${ }^{1}$ Department of Geophysics, School of Geology, Aristotle University of Thessaloniki, 54124 Thessaloniki - \\ Greece,aidona@geo.auth.gr,despi@geo.auth.gr
}

\begin{abstract}
Archaeomagnetism combines the magnetic properties of baked materials with Archaeology. The archaeomagnetic method can be applied to any kind of permanent - in situ or displaced- burnt structures, such as kilns, ovens, hearths, burnt floors, tiles, bricks and pottery fragments, the latter for intensity measurements only.

In this study we present the latest archaeomagnetic results from archaeological sites which are distributed in N. Greece (Polymylos, Sani, Thesssaloniki). The Natural Remanent Magnetization (NRM) and the magnetic susceptibility of the samples have been initially measured. The samples have been subjected to magnetic cleaning ( $A F$ and Thermal demagnetizations) and this procedure revealed the characteristic component of the ancient magnetic field. Rock magnetic experiments such as acquisition of the Isothermal Remanent Magnetization (IRM) and thermomagnetic analysis have been performed in pilot samples in order to identify the main magnetic carriers. Finally the secular variation curves for Greece and the SCHA.DIF.3K model were used in order to date these archaeological structures. This dating improved or modified the estimated archaeological ages.
\end{abstract}

Key words: archaeomagnetism, kilns, Northern Greece, dating .

\section{Introduction}

Archaeomagnetism is the discipline of palaeomagnetism which studies archaeological materials such as kilns, ovens, bricks and tiles and in general any kind of burnt clays, since they usually carry a stable magnetization that is almost entirely a thermoremanence. This stable magnetization has 'fossilized' the direction and the intensity of the field at the time and the place of the last firing. The main purpose of archaeomagnetism is first the establishment of accurate secular variation curves (SVC) from well dated -with other independent methods- structures and second the potential dating of relevant material for places and periods where such curves are available.

During the last decades several authors have studied the variations in intensity and direction of the geomagnetic field for the last 7000 and 5000 years respectively in Greece. Intensity data reported since 1980 (Liritzis and Thomas 1980) are by far more numerous (for a thorough review see DeMarco et.al., 2008) whereas directional data appeared in 1984 (Downey and Tarling, 1984). Recently new archaeomagnetic data have been obtained following severe selection criteria (Evans \& Kondopoulou, 1998, Kovacheva et al., 2000, Spatharas et al., 2000, Kondopoulou \& Spatharas, 2002, Tarling et al., 2004, Evans 2006) which leaded to the construction of new intensity (Spatharas, 2005, DeMarco et al., 2008) and directional SVC for Greece (DeMarco, 2007). 
In this paper we present new archaeomagnetic data obtained from three archaeological sites in N. Greece and we attempt to date them using the secular variation curves available for Greece and the regional model SCHA.DIF.3K (Pavon-Carrasco et al., 2009).

\section{Description of sampling sites}

Samples were collected from 3 different archaeological sites situated in N. Greece as shown in Fig.1 . Short description of the sites is given below, respecting a chronological order.

\section{Polymilos (ML and SO)}

The recent excavations, due to the construction of the New Egnatia Road, close to the ancient settlement of Polymilos, brought to light a part of an ancient city inhabited from the prehistoric times until the Late Antiquity. The main activity of the city was during the $3^{\text {nd }}$ century B.C. The two ceramic kilns sampled were in an excellent condition and destinated to preservation (Fig.1). Therefore sampling was delicate and restrained only to the kilns floor. A total of fifteen samples were obtained from both kilns (7 samples from ML and 8 samples from SO).

\section{Sani (Megali Kipsa - SAN8)}

Few years ago, the excavation of a palaeochristian farm in Megali Kipsa of Kassandra has started. This complex consists of several buildings but the most impressive feature of the site is the ceramic kilns complex. The archaeological excavation brought to light nine, well preserved, kilns while the remains of other three were detected. From the archaeological investigation it appeared that this complex operated as a small ceramic industry not only for the construction of the settlement but also for providing bricks to other adjacent areas. On the basis of coins found in the site it is believed that these kilns started to be in action at the beginning of the $4^{\text {th }}$ Century AD. From this site one kiln was sampled (Fig.1) and in total 10 samples were collected.

\section{Thessaloniki (RS1)}

The archaeological excavations in the centre of Thessaloniki due to the construction of the subway revealed a laboratory area with several ceramic kilns in front of the actual main Railway Station. The archaeological information indicates that this workshop area was in use for several centuries (Roman and Byzantine times) as it is shown from the coins and the potteries found in the site. One kiln was sampled and in total eighteen independently oriented samples were obtained.

\section{Sampling and measurements}

All the collected samples were independently oriented with regard to the geographic north and the local horizontal plane by means of a small plexiglas plate glued on the top of the material. The dip was measured with a bubble inclinometer and the azimuth by using magnetic and sun-compasses.

A total of 43 hand samples were collected from the four kilns and from them 149 specimens (standard cylinders or $2 \times 2 \mathrm{~cm}$ cubes) were prepared in the laboratory.

The remanent magnetization was measured using a Minispin magnetometer (Molspin, Newcastle, UK). Alternating Field (AF) demagnetization was performed at the field strength of 5-60mT with 5 mT interval and $60-100 \mathrm{mT}$ with 10mT interval by using an Molspin-MSA2 AF- tumbler demagnetizer (Molspin, Newcastle, UK). The magnetic susceptibility was measured using a KLY-2 susceptibility bridge (Agico, Brno, Czech Rep.). The anisotropy of magnetic susceptibility was measured using a Kappa bridge KLY 2 and a MF K1. Anisotropy parameters i.e lineation (L), foliation (F), degree of anisotropy (P'), shape factor (T) reflecting the alignment of particles and shape of magnetic susceptibility ellipsoid, have also been calculated using the program ANS 21 (Jelinek, 1977). 


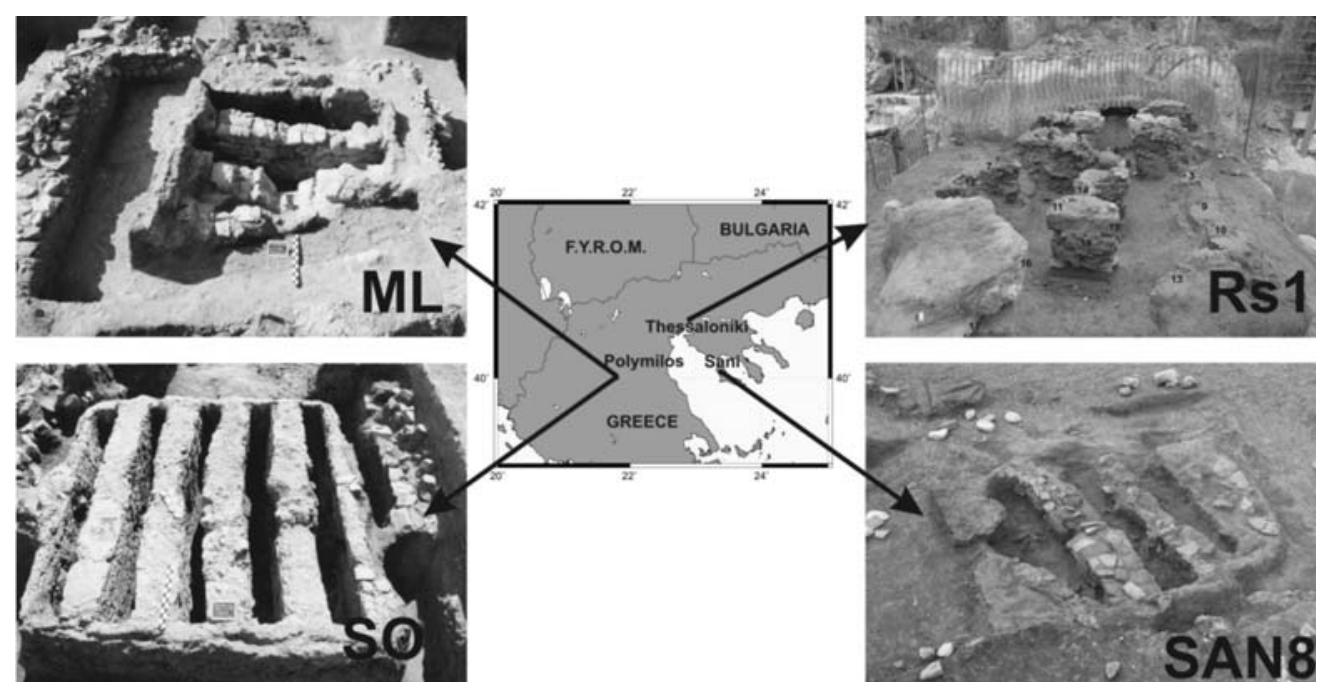

Fig. 1: Simplified map showing the geographical distribution of the sampled archaeological sites and the corresponding photos of the kilns: on the left side the two kilns (ML and SO) from Polymilos are shown, while on the right side the kiln (RS1) from Thessaloniki and the kiln SAN8 from the archaeological site of Megali Kipsa are presented.

High-temperature behavior of magnetic susceptibility (thermomagnetic analysis) for determination of the Curie point of magnetic minerals present in the material was performed on a Bartington susceptibility meter with a furnace attached, and a Kappa bridge KLY 2. Magnetic susceptibility changes were recorded continuously from room temperature up to $700^{\circ} \mathrm{C}$ and back.

In pilot samples from each site an isothermal remanent magnetization (IRM) was imparted with a pulse magnet and a maximum field of $2.5 \mathrm{~T}$ and a stepwise acquisition curves of IRM were obtained for selected samples.

Thermal stepwise demagnetisation of composite IRM (Lowrie, 1990) was performed in selected samples in order to obtain unblocking temperatures of soft-, medium- and hard magnetic components. The following strengths of the magnetic field to induce the three components were used: soft $-0.1 \mathrm{~T}$, medium $-0.5 \mathrm{~T}$, hard $-2 \mathrm{~T}$.

\section{Results}

\subsection{Rock magnetism}

The identification of the magnetic carriers is critical in order to evaluate the suitability of material for obtaining reliable archaeomagnetic results. IRM curves revealed the dominance of magnetite (or titanomagnetite) in most of the cases (Fig.2a). Only in the case of Thessaloniki (RS1) two distinct groups are observed. One, with a low coercivity component which saturates at about $100 \mathrm{mT}$ and a second one with two magnetic mineral phases, with low coercivity and high coercivity respectively which is not able to saturate at $1200 \mathrm{mT}$. The thermal demagnetization of the 3 - axes composite IRM results are shown in Fig.2b.The demagnetization along the $\mathrm{x}$ axis (soft component) revealed unblocking temperatures from $580^{\circ}$ to $650^{\circ} \mathrm{C}$ indicating magnetite with different Ti contents and small portions of hematite. In the case of the RS1 the highest magnetization is recorded along the $\mathrm{z}$ axis (hard component) with a sharp decrease at about $200^{\circ} \mathrm{C}$, indicative for the presence of goethite. The variation of the low-field susceptibility with temperature exhibits a stable behav- 
Table 1. Mean anisotropy parameters for the magnetic susceptibility anisotropy ellipsoids for the studied sites. $\mathrm{N}=$ number of samples, $\mathrm{L}=$ lineation, $\mathrm{F}=$ Foliation, $\mathrm{P}=$ anisotropy degree, $\mathrm{T}=$ shape parameter of Jelinek (1981).

\begin{tabular}{|l|c|c|c|c|c|}
\hline Site & $\boldsymbol{N}$ & $\boldsymbol{L}$ & $\boldsymbol{F}$ & $\boldsymbol{P}$ & $\boldsymbol{T}$ \\
\hline Thessaloniki & 23 & 1.019 & 1.055 & 1.075 & 0.452 \\
\hline Polymilos & 35 & 1.032 & 1.040 & 1.058 & 0.598 \\
\hline
\end{tabular}

a
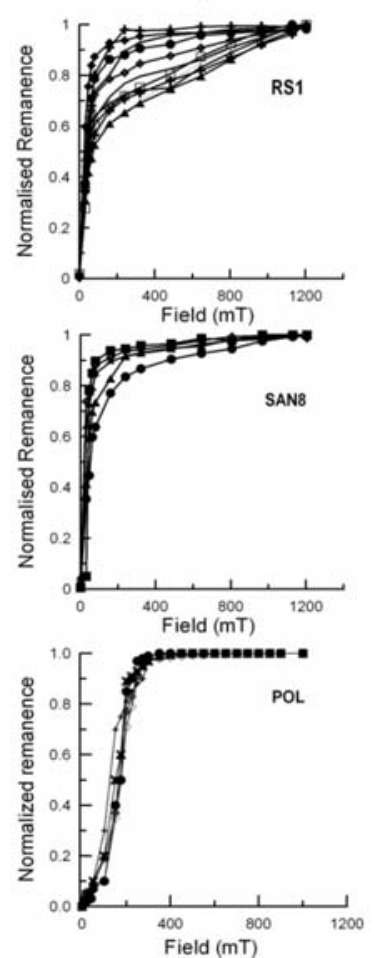

b
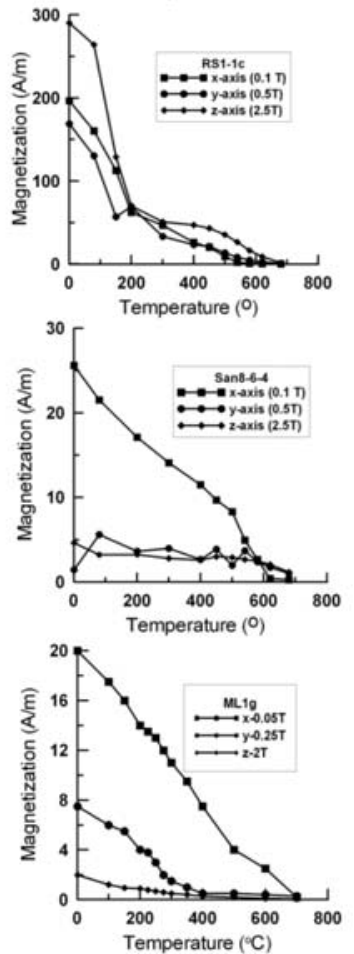

c
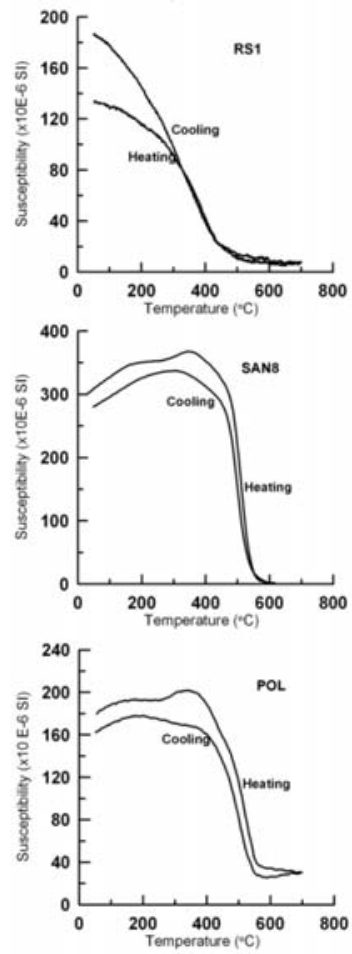

Fig. 2: Rock magnetic experiments. a) IRM curves from the three archaeological sites. b) Demagnetization of the 3-axes composite IRM of pilot samples, and c) thermomagnetic curves. (For details see text).

ior, even if the shape of the thermomagnetic curves differs from sample to sample. Heating and cooling curves are almost reversible, indicating minor mineralogical changes. The Curie temperatures vary from $500^{\circ}$ to $580^{\circ} \mathrm{C}$, characteristic for the presence of magnetite or titanomagnetite.

The anisotropy of magnetic susceptibility was measured in selected samples from the archaeological sites of Thessaloniki and Polymilos. Since the effect of the shape anisotropy can be substantial for bricks and tiles and minor for baked clays, we performed indicative anisotropy measurements to the samples of Sani. The anisotropy degree ranges from $2 \%$ to $4 \%$ which is insignificant. The mean anisotropy parameters for the other two studied sites are reported in Table 1 . The shape of the AMS ellipsoid is oblate $(\mathrm{T}>0)$ in both cases. Generally, the samples were not particularly anisotropic, with the degree of anisotropy (P) varying between 2 and 14\% for Polymilos and a mean value of 1.058 (Spatharas, 2005), while in Thessaloniki, samples seem to be more anisotropic with P values varying from $4 \%$ to $15 \%$ and a mean value of 1.075 . 


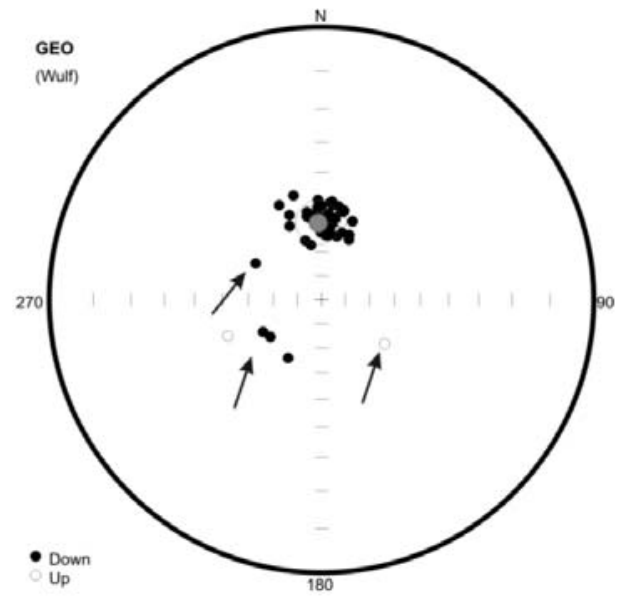

Fig. 3: Stereographic projection of the NRM distribution of samples from Thessaloniki. Dots represent specimens measurements (full dots correspond to positive inclinations while open dots indicate negative inclinations). Black arrows point to the rejected data.

\subsection{Archaeomagnetic results}

The NRM of all 149 specimens from the three archaeological sites has been measured using a Molspin spinner magnetometer. At least one specimen from each sample was demagnetised, in order to define the characteristic magnetic component. The NRM directions seem to group satisfactorily. Nevertheless, in some cases directions of specific samples were rejected since they show values totally different from the expected ones as it is seen in the stereographic projection of the distribution of NRM (Fig. 3).

The magnetic cleaning reveals the presence of one stable component of magnetization with a weak viscous component (Fig.4a). The majority of the samples were demagnetised successfully up to $100 \mathrm{mT}$, but there were cases where the demagnetization was not complete up to $100 \mathrm{mT}$ (Fig.4b).

The demagnetization of the rejected samples (due to their deviating NRM directions) did not modify their directions. With a more careful observation of these samples position into the kilns, we noticed that they gathered either in the entrance or in the outer part of the kiln and most probably they have not been sufficiently burnt and therefore in their original magnetization was not totally cancelled (Jordanova et al, 2004, Aidona et al., 2008). Consequently, these results were not included to the computation of the mean characteristic remanence direction of the sites.

The characteristic remanent magnetization (ChRM) directions were calculated using the principal component analysis (Kirschvink, 1980). In the final calculations we did not take into consideration samples with variations in declinations bigger than $20^{\circ}$ with respect to the mean value and $\mathrm{a}_{95}$ bigger than $10^{\circ}$. The mean calculated directions and their statistics are presented in Table 2 and their stereographic projection in Fig. 5.

In order to obtain a full archaeomagnetic record for the archaeological site of Sani, paleointensity measurements were performed. A total of 11 specimens with a volume of about $0.75 \mathrm{~cm}^{3}$ have been analyzed using the continuous high temperature magnetization measurement method, shortly defined as the "Triaxe" technique (Le Goff and Gallet, 2004; Gallet et al., 2006). The technique involves several continuous zero field heating and cooling cycles up to a maximal temperature of $650^{\circ}$ $\mathrm{C}$ with a rate of $25^{\circ} \mathrm{C} / \mathrm{min}$ and one in-field cooling cycle. During the latter cycle, a field of 40 or 50 $\mu \mathrm{T}$ was applied parallel to the NRM. Magnetization was monitored through all cycles with a three- 

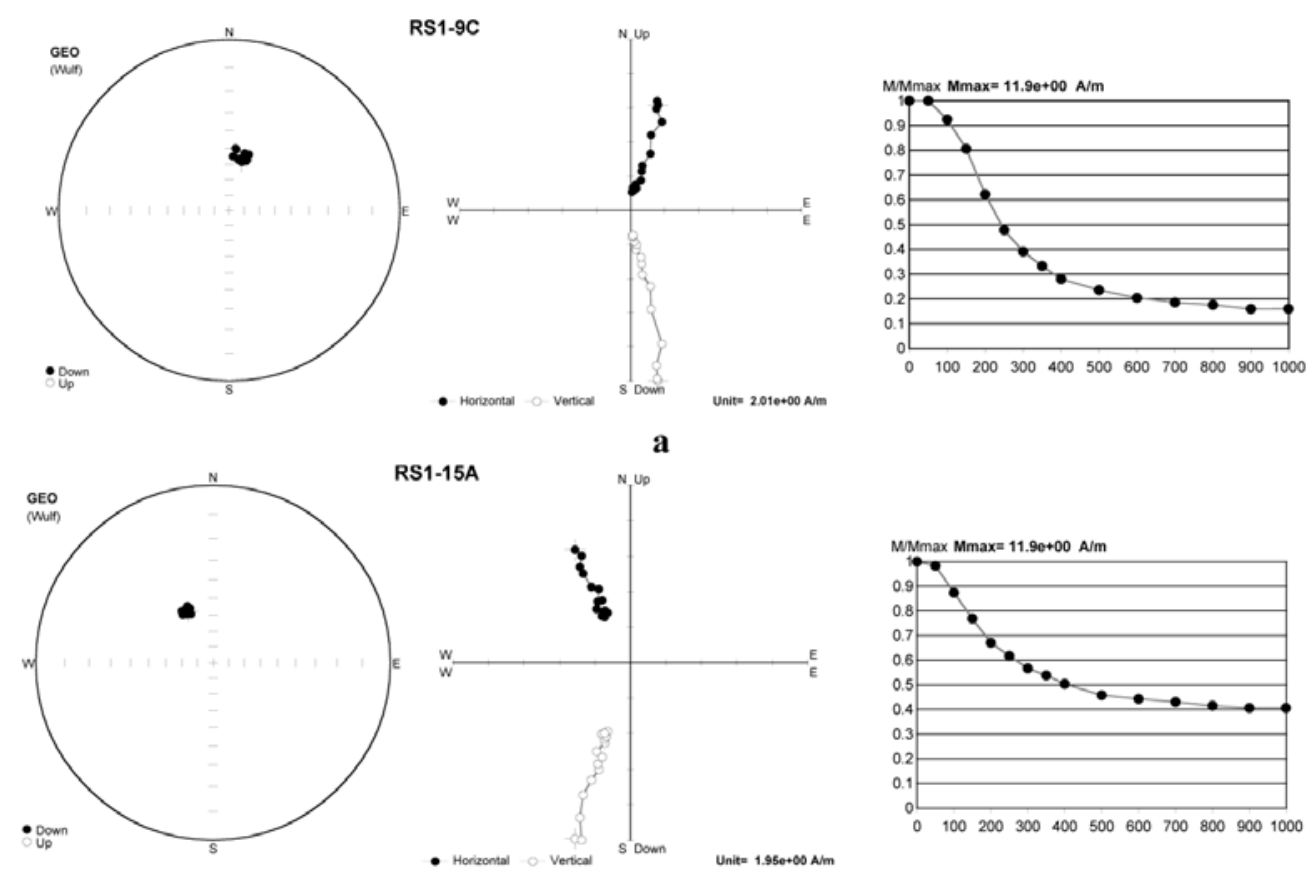

b

Fig. 4: Stereographic projection, Zijderveld diagram and demagnetization curve of a) specimen where the demagnetization is successful up to $100 \mathrm{mT}$, b) specimen where the demagnetization is not complete up to $100 \mathrm{mT}$

Table 2. Mean ChRM directions for each archaeological site. n: number of samples; D: declination; I: inclination; $F$ : intensity; $\mathrm{k}$ : precision parameter; $\mathrm{a}_{95}$ :semi-angle of cone of confidence

\begin{tabular}{|l|c|c|c|c|c|c|c|c|c|}
\hline Site & Lat/Long & $\boldsymbol{n}$ & $\boldsymbol{D}^{\circ}$ & $\boldsymbol{I}^{\circ}$ & $\boldsymbol{k}$ & $\boldsymbol{a}_{95}$ & $\boldsymbol{F}(\boldsymbol{\mu T})$ & $\begin{array}{c}\text { Archaeological } \\
\text { age }\end{array}$ & $\begin{array}{c}\text { Archaeomagnetic } \\
\text { dating }\end{array}$ \\
\hline Polymilos & $40^{\circ} / 21.9^{\circ}$ & 14 & 348.1 & 52.6 & 57.18 & 5.3 & 66.0 & $300-200$ B.C & $393-170 \mathrm{BC}$ \\
\hline Sani & $40.07^{\circ} / 23.3^{\circ}$ & 6 & 357.2 & 49.1 & 159.8 & 5.3 & 61.9 & 3 rd- $4^{\text {th }}$ A.D & $350-475 \mathrm{AD}$ \\
\hline Thessaloniki & $40.7^{\circ} / 23.1^{\circ}$ & 14 & 358.5 & 56.9 & 81.73 & 4.4 & - & 4 th $-13^{\text {th }}$ A.D & $700-1054 \mathrm{AD}$ \\
\hline
\end{tabular}

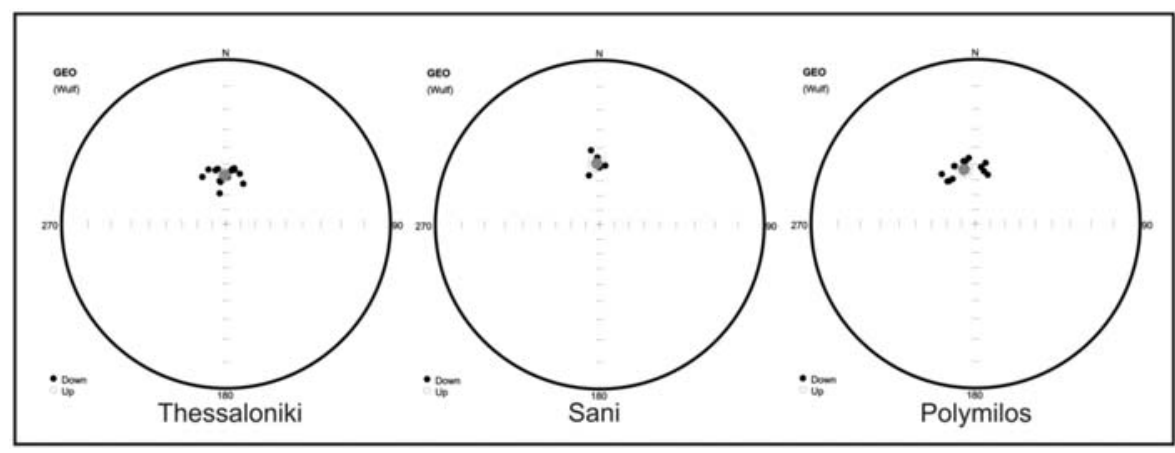

Fig. 5: Stereographic projection (lower hemisphere) of the samples (black dots) used for the calculation of mean directions (red dot) for the three sites respectively. 

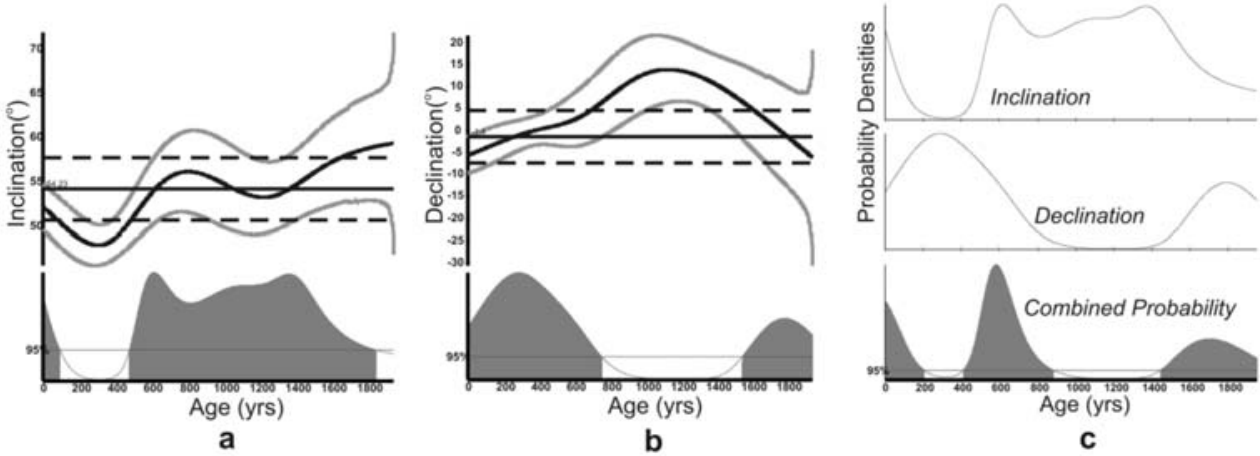

Fig. 6: Archaeomagnetic dating of Thessaloniki site. a,b) In the upper part of the graphs, the reference curves for inclination and declination (black line) with its error bands (grey lines) respectively. The mean site direction (relocated to Athens) is depicted with its error (dashed lines). In the lower part the probability densities for I and D, respectively at $95 \%$ of probability level. c) final dating after combining the probabilities of (a) and (b).

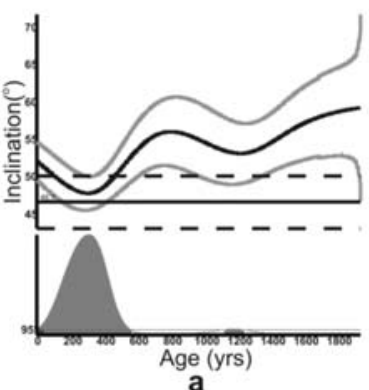

a

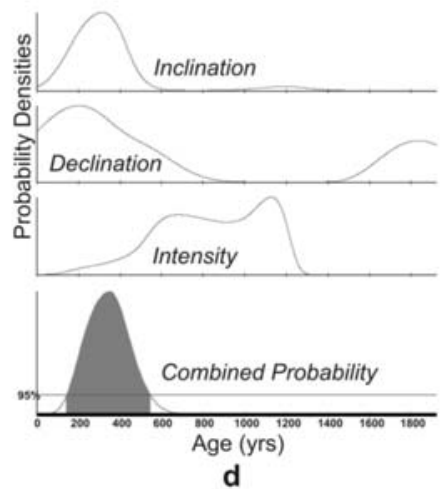

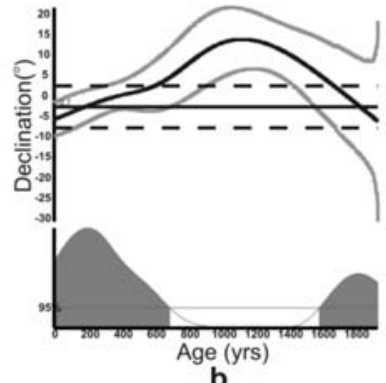

b

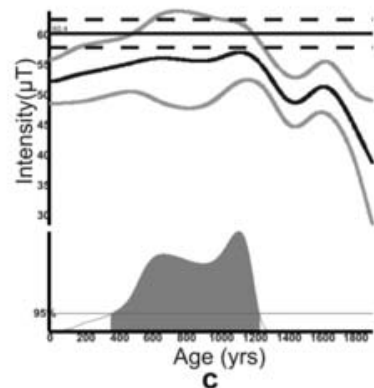

C

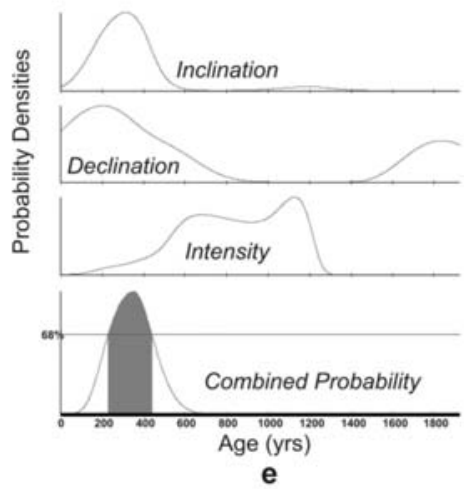

Fig. 7: Archaeomagnetic dating of Sani site. a,b,c) Dating of inclination, declination and intensity respectively. Symbols as Fig.6. d,e) final dating after combining the probabilities of (a), (b) and (c) for 95\% and 68\% probability respectively.

axis vibrating sample magnetometer within a Helmholtz coil system covered by a mu-metal shield. The mean intensity value calculated from the samples which met all required criteria (details in Gallet et al., 2006) is $61.9 \pm 2.2 \mu \mathrm{T}$. 

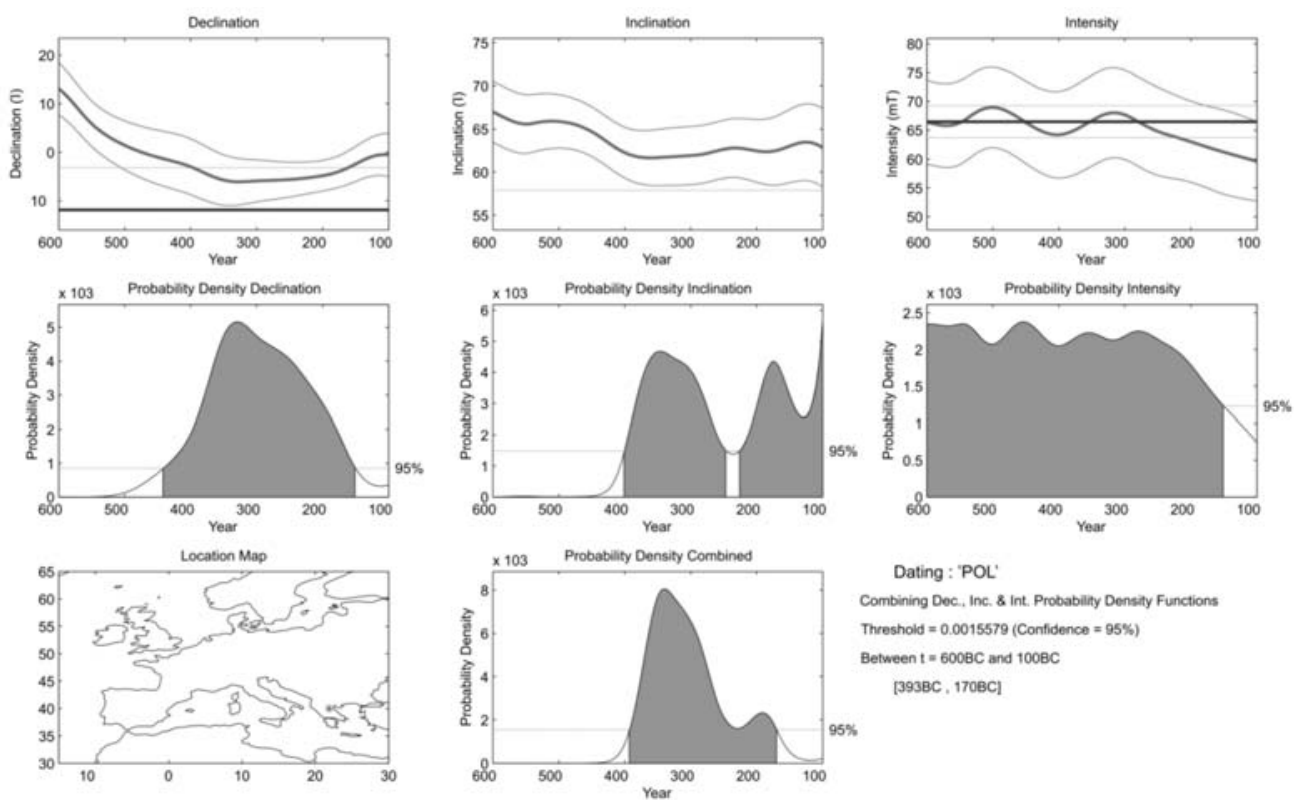

[3938C, $170 \mathrm{BC}]$

Fig. 8: Archaeomagnetic dating of Pol at $95 \%$ of probability level, using the declination, inclination and intensity curves as proposed by Pavon-Carrasco et al., 2009.

\section{Archaeomagnetic dating}

In the last decade archaeomagnetic dating became an attainable and common practice due to the development in statistical treatment of archaeomagnetic data based on bivariate statistics or Bayesian hierarchical technique (Le Goff et al., 2002; Lanos et al., 2005).

The archaeomagnetic dating is possible only in regions where a well established secular variation curve is available. The first directional SVC for Greece have been constructed by DeMarco (2007), while for the intensity the first attempt was made by Spatharas (2005). A new, improved version was published by DeMarco et al., 2008.

In order to date archaeomagnetically our results, the obtained data for the studied areas (Table 2) have been recalculated to the geographical coordinates of Athens, where the Greek SVC also referred to as a reference site. The relocation was made by using the virtual geomagnetic pole (VGP) method proposed by Noel and Batt (1990). The dating was performed by using the Bayesian hierarchical approach (Lanos et al., 2005). This method allows the calculation of the probability densities separately for each geomagnetic field element after comparison with the reference SV curves. The final dating interval is obtained by combining the separate probability densities in order to find the best solution.

In Figs. 6,7 the final dating for Thessaloniki and Sani sites is presented. For Thessaloniki site, the comparison of the directional data gives three time intervals: 0-205AD, 410-880AD and 1445$1950 \mathrm{AD}$ at $95 \%$ confidence level. According to the archaeological findings the most probable interval is the second one (410-880AD). This time interval represents the last firing of the kiln. Even if the reference SVC for this time span is not very well constrained, the estimation obtained from the dating is more precise and narrower than the archaeological one (400-1300AD). 
For Sani, the full archaeomagnetic field vector was used for the dating. The combination of the three geomagnetic elements (D, I, F) yields a time interval from 144-545AD at 95\% confidence level. According to the archaeological findings the kiln is dated in the end of the $3^{\text {rd }}$ century or beginning of the $4^{\text {th }} \mathrm{AD}$. If instead of $95 \%$ of probability the $68 \%$ is calculated then, the obtained time interval is 229-440AD, which is much smaller and closer to the archaeological estimations (Fig.7).

For the archaeological site of Polymilos, the archaeointensity value had been already estimated by Spatharas, (2005). Since this value is used by DeMarco et al., (2008) for the elaboration of the new intensity SV for Greece we did not use the Greek curves for dating this site in order to avoid any circular reasoning. Instead, the regional archaeomagnetic model for Europe for the last 3000yrs, SCHA.DIF.3K proposed by Pavon-Carrasco et al., (2009) was used. The obtained time period, when taking into account the archaeological constraints is 393-170 BC. (Fig.8).

\section{Conclusions}

The material studied here has proved to be reliable for an accurate recording of the ancient geomagnetic field. This is confirmed by absence of alteration and strong anisotropy, and the presence of multiple magnetic carriers. The grouping of the obtained directions is estimated satisfactory with $\mathrm{a}_{95}$ parameter lying at the limit of worldwide accepted as trustworthy values. A further control of the obtained D,I values by comparing them to the existing dataset for Greece (DeMarco, 2007) shows a very satisfactory convergence in all but one cases: the I value of Polymilos is by $10^{\circ}$ lower than the other data. The $\mathrm{D}$ values are slightly diminishing versus age. Though the existing error bars do not allow a firm conclusion, this could be related to the westward drift observed for mid-latitude azimuthal motions over the last 3000yrs, for the time period 800BC-900AD (Dumberry and Finlay, 2007).

A continuing study in the above archaeological sites will possible clarify this observation.

\section{Acknowledgments}

The authors would like to thank the archaeologists L. Acheilara, K. Papaggelos, T. Tsanana and G. Karamitrou who have provided permissions and valuable information for the studied archaeological sites presented here. Dr. E. DeMarco is warmly thanked for providing the data of the Greek SVC for the dating of the studied areas and Prof. Ph. Lanos for making available Rendate software. F. Pavon-Carrasco is thanked for performing the dating for Polymilos. M. LeGoff is warmly acknowledged for allowing the use of the Triaxe magnetometer at St.Maur (France), as well as the initiation of D.K to the method and interpretation.

\section{References}

Aidona E., Scholger, R., Mauritch, H., Perraki, M., 2008. Remanence acquisition in a Roman-style gold furnace. Physics and Chemistry of the Earth, 33, 438-448.

DeMarco, E., 2007. Complete magnetic and archaeomagnetic measurements in archaeological sites: contribution to the SVC for Greece. PhD Thesis, Aristotle University of Thessaloniki, Thessaloniki, 293pp.

DeMarco, E., Spatharas, V., Gomez-Paccard, M., Chauvin, A., Kondopoulou, D., 2008. New archaeointensity results from archaeological sites and variation of the geomagnetic field intensity for the last 7 millennia in Greece. Phys. and Chem. of the Earth 33, 578-595.

Downey, W.S., Tarling, D.H., 1984. Archaeomagnetic dating of Santorini volcanic eruptions and fired destruction levels of Late Minoan civilization. Nature 309, 519-523.

Dumberry M., Finlay C., 2007. Eastward and westward drift of the Earth's magnetic field for the last 
three millennia. Earth Planet. Sci. Let., 254, 146-157.

Evans, M.E. and Kondopoulou, D., 1998. Archaeomagnetism in Macedonia, Greece: A progress Report. Phys. Chem. Earth, 23, (9-10), 1027-1028.

Evans, M.E., 2006. Archaeomagnetic investigations in Greece and their bearing on geomagnetic secular variation. Phys. Earth Planet. Int., 159, 90-95. doi:10.1016/j.pepi.2006.06.005.

Gallet, Y., A. Genevey, M. Le Goff, F. Fluteau, and S. A. Eshraghi 2006. Possible impact of the Earth's magnetic field on the history of ancient civilizations, Earth and Planetary Science Letters, 246, 17-26.

Jelinek, V., 1977. The statistical theory of measuring anisotropy of magnetic susceptibility of rocks and its applications. Geofizika, Brno.

Jelinek,V., 1981. Characterization of the magnetic fabric of rocks. Tectonophysics, 79, 63-67.

Jordanova, N., Kovacheva, M., Kostadinova, M., 2004. Archaeomagnetic investigation and dating of Neolithic archaeological site from Boulgaria. Phys. Earth Planet. Int., 147, 89-102.

Kirschvink, J.L., 1980. The least-squares line and plane and the analysis of palaeomagnetic data. Geophysical Journal of the Royal Astrological Society, 62: 699-718.

Kondopoulou, D., and Spatharas, V., 2002. Magnetomineralogy of archaeomagnetic materials from N. Greece. Proc. 5th European Meeting on Ancient Ceramics, Athens 1999. In: Kilikoglou, V., Hein, A., Maniatis Y. (Eds.), Modern trends in scientific studies on ancient ceramics. BAR International Series, 1011, 389-402.

Kovacheva, M., Spatharas, Y., Liritzis, Y., 2000. New archaeointensity results from Greek materials. Archaeometry, 42 (2), 415-429.

Lanos, Ph., Le Goff, M., Kovacheva, M., Schepp, E., 2005. Hierarchical modelling of archaeomagnetic data and curve estimation by moving average technique. Geophys. J. Int., 160, 440-476.

Le Goff, M., Gallet, Y., Genevey, A., Warme, N., 2002. On archaeomagnetic secular variations curves and archaeomagnetic dating. Phys. Earth Planet. Int., 134, 203-211.

Le Goff, M. and Y. Gallet, 2004. A new three-axis vibrating sample magnetometer for continuous hightemperature magnetization measurements: applications to paleo- and archeo-intensity determinations, Earth and Planetary Science Letters, 229, 31-43.

Liritzis, Y. and Thomas, 1980. Palaeointensity and thermoluminiscence measurements on Cretan kilns from 1300 to 2000 BC. Nature, vol.283, 54-55.

Lowrie, W., 1990. Identification of ferromagnetic minerals in a rock by coercivity and unblocking temperature properties. Geophys. Res. Let., 17 (2), 159-162.

Noel, M., Batt, C., 1990. A method for correcting geographically separated remanence directions for the purpose of archaeomagnetic dating. Geophys. J. Int., 102, 753-756.

Pavón-Carrasco, F. J., Osete, M.L., Torta J.M., Gaya-Piqué L.R., 2009. A regional archaeomagnetic model for Europe for the last 3000 years, SCHA.DIF.3K: Applications to archaeomagnetic dating. Geochemistry, Geophysics, Geosystems, 10, Q03013, doi: 10.1029/2008GC002244.

Spatharas, V., 2005. Archaeomagnetic and magnetic measurements in archaeological materials in Macedonia and Thrace (N. Greece). PhD Thesis, Aristotle University of Thessaloniki, Thessaloniki, 179pp (in Greek).

Spatharas, V., Kondopoulou, D., Liritzis Y., and G. Tsokas., 2000. Archaeointensity results from two ceramic kilns from N. Greece. J. Balkan Geophys. Soc., 4, 67-72.

Tarling, D.H., Kondopoulou, D. and Spatharas, V., 2004. An archaeomagnetic study of the LM IB Kilns. In: Soles, J.S., Davaras, C. (Eds.), Mochlos IC - Period III. Neopalatial Settlement on the Coast: The Artisans' Quarter and the Farmhouse at Chalinomouri. The small Finds. Prehistory Monographs 9, INSTAP Academic Press, Philadelphia, Pennsylvania, 2004. 